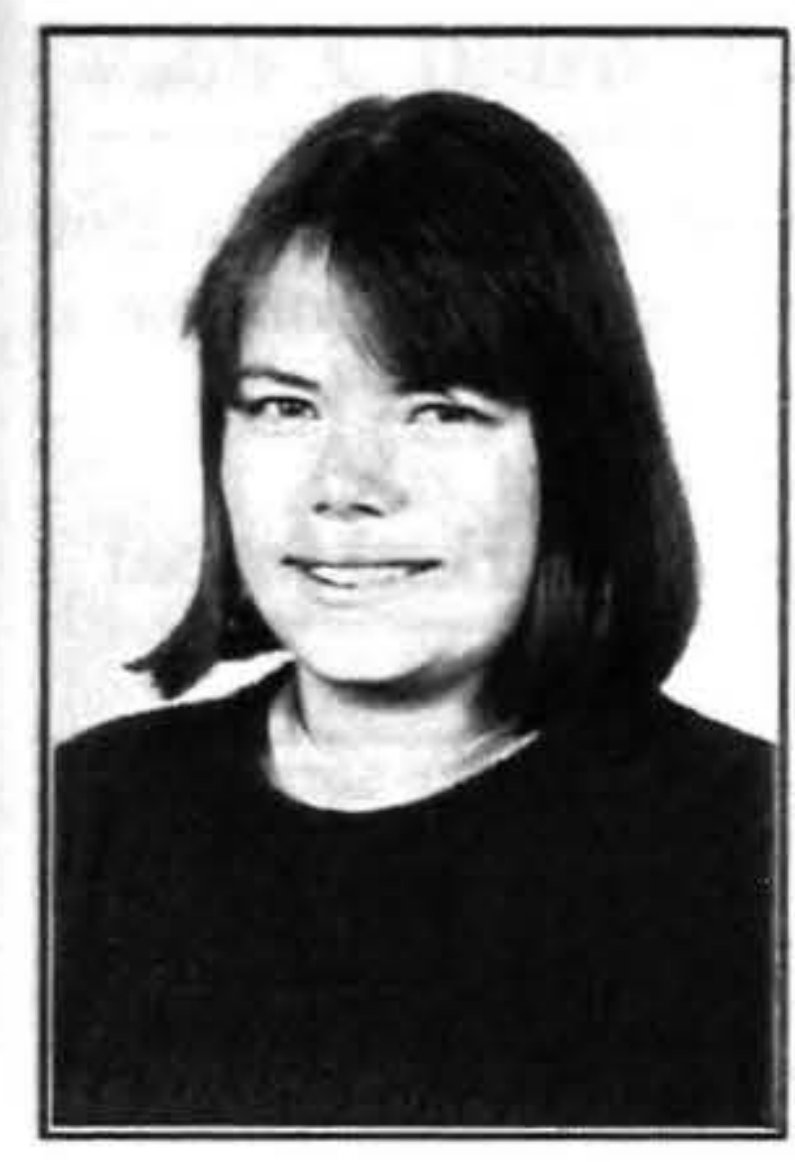

\title{
SECONDARY SCHOOL STUDENTS IN PAID WORK
}

\author{
Debbie Peterson \\ Victoria University of Wellington
}

\begin{abstract}
This paper looks at the experiences of sixth and seventh form secondary school students who work part-time. The research is based in the Wellington region and focuses on the students' knowledge of employment contracts, pay and working conditions, reasonsfor working, and the effect of working on the students' schooling. I will present results from the first part of my research - a written questionnaire distributed to over 200 students in paid work.
\end{abstract}

Two years ago at the last LEW conference, David Hanna and I presented a paper summarising research that we had undertaken looking at the experiences of young people who worked 20 hours or more per week (Hanna and Peterson, 1993).

One decision made at the beginning of that research was that a separate study was needed to address the issues concerning secondary school students who worked part time.

Working secondary school students have come to public attention many times over recent years. This attention has mainly focused on their long work hours, low pay, and monotonous tasks (Swain, 1990; Boyd, 1993). Interest in the area intensified firstly after minimum wage protection was lost for under 20 year olds with the abolition of Awards under the ECA and secondly when the Minimum Youth Wage was introduced in March 1994 for 16-19 year olds at the rate of $\$ 3.68$ an hour.

The 1991 Census indicates that $19 \%$ of school students aged 15-17 years were in part-time employment, as well as $16 \%$ of $18-19$ year olds. These figures are likely to be an underestimate due to the number of students working in the 'informal economy'. They do not pay tax on their earnings and therefore may not declare their employment on Census forms.

The research for the M.A. (Applied) in Social Science Research at Victoria University looks specifically at the experiences of secondary school students who work during the school term. It covers their knowledge of employment contracts, working conditions, reasons for working and the effects of working on schooling.

This paper reports only those aspects that to employment. A fuller discussion of this data plus information that relates more to school work and the social aspects of working (e.g the reasons for working, what the money earned is used for, etc.) will be available when my thesis is completed.

\section{Methodology}

I approached four schools in the Wellington region for permission to administer a written questionnaire to their sixth and seventh form students in paid work. Sixth and seventh formers were chosen mainly due to the need to restrict the sample size and because parental permission would not be needed for them to participate.

The schools were chosen to obtain a good geographical spread and mix of students and to get a balance of single sex and co-educational schools.

The questionnaire was distributed in the time between Easter and the end of the first term 1994. This was in order to interfere as little as possible with the students' examination timetables. Two of the schools got their students to fill in the questionnaires during form time, another asked all those students who were working to remain behind after an assembly and fill them in, whilst the last school asked all those who were working to report to a specific room during a study period to fill in the questionnaires.

All the students concerned were also asked if they wished to participate in focus groups to discuss further the issues surrounding part time work. There were enough volunteers to run a group at each of two schools. The groups were held at the schools concerned just after the students' mid year exams, and lasted approximately an hour each.

\section{Results}

A total of 219 students from four schools filled in the questionnaire. The highest response rate from the schools surveyed was approximately one third of all the sixth and seventh formers at the school. Two of the schools had 
significantly lower response rates, but that was possibly due to the different ways the questionnaires were administered rather than because fewer were working.

There was a gender imbalance in the sample due to the high response from the all girls school and the low response from the all boys school. 139 of the respondents were female ( 63 percent), 79 were male ( 36 percent).

The schools that I chose all had a mix of ethnic groups: 74 percent of the sample described themselves as New Zealand European (Pakeha), 10 percent Maori, 5 percent Pacific Island, and 9 percent as another ethnic group.

There was a fairly even split of sixth (47\%) and seventh formers $(53 \%)$, and because these were the only forms surveyed, most of the respondents were aged 16 and 17 (93 percent). A small number were aged 15 and 18 (1 percent and 5 percent respectively).

Seventeen percent of the sample had more than one job most of these having two, but five students had three jobs and one had four.

\section{Type of Work}

The classification system that I used for the type of work undertaken by the students was a mixture of occupation and worksite. The numbers involved in each type of work differed by gender, see table 1 .

\section{Table 1. Most common type of work}

\begin{tabular}{ll}
\hline Males & \\
Supermarket & $33 \%$ \\
Newspaper Delivery & $11 \%$ \\
Fastfood Outlet & $9 \%$ \\
Other Retail & $6 \%$ \\
Milk Delivery & $5 \%$ \\
Cleaning & $5 \%$ \\
\hline Females & \\
Supermarket & $25 \%$ \\
Other Retail & $13 \%$ \\
Cleaning & $11 \%$ \\
Babysitting & $8 \%$ \\
Fast food outlet & $7 \%$ \\
\hline
\end{tabular}

All of these common jobs are low skilled and in the service sector. The most popular type of work for both sexes was supermarket work. This is not surprising, as all bar one of the schools were situated near major supermarkets.

Other kinds of work that the students were doing included child care, factory work, farm work, lawn mowing, resthome work, working on a rifle range, refereeing sport etc.

\section{Hours of Work}

The students were asked several questions about their hours worked in order to get as specific information as possible; table 2.

Table 2. Total hours worked for all jobs per week

\begin{tabular}{llll}
\hline Hours & Female & Male & Total \\
\hline $0<5$ & $26 \%$ & $22 \%$ & $24 \%$ \\
$5-10$ & $39 \%$ & $22 \%$ & $33 \%$ \\
$10-15$ & $24 \%$ & $27 \%$ & $25 \%$ \\
$15-20$ & $7 \%$ & $16 \%$ & $11 \%$ \\
$20+$ & $4 \%$ & $13 \%$ & $8 \%$ \\
& $(\mu=139)$ & $(\mu=79)(\mu=219)$ \\
\hline
\end{tabular}

The median number of hours worked in total for all jobs was 8 hours ( 10.5 for males, 8 for females). 19 percent of the students were working 15 hours or more per week. Two students worked, on average, for 40 hours per week (in one job). One of these (a seventh former) said on his questionnaire that he was trying to set up his own business, which is why he worked such long hours.

Table 3 shows the number of students who worked regularly and the days and hours that they worked.

Sunday is the least popular working day, followed by Tuesday. Nearly all the students who worked during the week did so after school rather than before school. (Nine students worked only before school during the week, whilst a further student worked both before and after school.)

Of the 163 students who said that they worked regular hours, 36 percent said that they worked only during the week and not at weekends, whilst 10 percent worked during the weekend only. The greatest majority worked one or two days during the week and one day at weekends. One student worked seven days a week.

One of the areas that I will be addressing in my thesis will be how the number of hours a student works per week or the distribution of those hours affects their school work.

\section{Size of the Workplace}

The students were asked "How many people, on average, work in your workplace when you do?" as it has been suggested that those in larger work sites are less open to 'exploitation' (Parker, 1990). Forty five percent of the students worked in sites with less than five other people.

Only seven percent of the students had started their jobs in the four weeks before the survey. Twenty percent had been 


$\begin{array}{lccccccc} & \text { Mon } & \text { Tues } & \text { Wed } & \text { Thurs } & \text { Fri } & \text { Sat } & \text { Sun } \\ \text { No. working } & 70 & 66 & 75 & 80 & 85 & 72 & 57 \\ \text { Min. hours worked } & 0.5 & 0.5 & 0.5 & 0.5 & 0.5 & 0.5 & 0.5 \\ \text { Max. hours worked } & 6.5 & 6.5 & 6.5 & 6.5 & 7.0 & 12 & 11.5 \\ \text { Med. hours worked } & 2 & 2 & 2 & 2 & 2.5 & 4.5 & 4.5\end{array}$

in the same job for six to twelve months, and 37 percent for more than one year. It is important to know this information in order to work out entitlement to sick leave and paid annual holidays (see later in this paper).

\section{How did they find their jobs?}

The students generally found their work through either relatives ( 25 percent) or friends ( 23 percent). When the relative was specified, it was usually the student's mother (29 percent) or brother/sister (27 percent). Thirteen percent responded to an advertisement (in the newspaper or on a notice board), and the same number directly approached employers themselves. In another 10 percent of cases, the employer approached the student. This highlights the importance of networks when it comes to looking for a job.

Table 4. Number in workplace

\begin{tabular}{lll}
\hline \multicolumn{2}{l}{ No. of People } & Total \\
\hline 1 & 33 & $15 \%$ \\
$2-5$ & 66 & $30 \%$ \\
$6-10$ & 31 & $14 \%$ \\
$11-20$ & 28 & $13 \%$ \\
$21-50$ & 30 & $14 \%$ \\
$51+$ & 27 & $12 \%$ \\
Total & 219 & $100 \%$ \\
\hline
\end{tabular}

\section{Union membership}

Very few of the students were union members (six percent). Of those that were, two thirds were supermarket workers (13 percent of all the supermarket workers).

In both the focus groups the students could see the benefits of joining a union, but gave various reasons why they did not belong. Whilst cost was cited as a factor, it didn't seem to be that much of an impediment. Most said that the fees they would have to pay were very low compared to their earnings.

All saw the main advantage of unions as protecting workers' rights and gaining pay rises. However, some of the students in the first group said that they didn't work enough hours for the small pay rises that they got to count for very much, so they did not have much enthusiasm for joining the union.

Joining a union was seen to be a major commitment. The sentiment was that while it wouldn't hurt to join, it wasn't worth it as they were only working part time, or were not planning to stay in that job for much longer.

\section{Pay and working conditions}

The students were asked both how much they earned before tax per hour and per week. The data that I am presenting here concerns hourly pay rates. When calculating these pay rates I excluded the newspaper deliverers for reasons given below.

The median rate per hour before tax was $\$ 6.00$. The least anyone was paid was $\$ 2.30$ per hour, the most, $\$ 40.00$. This young person was a highly specialised contract worker. Those that paid tax earned a median rate of $\$ 5.95$ per hour compared to $\$ 6.20$ for those not paying tax.

The seventeen year olds earned more than the sixteen year olds ( $\$ 6.50$ per hour compared to $\$ 5.57$ per hour). There was no difference in the median hourly pay for male and female students - though the mean hourly rate for females was slightly higher than for males. The Maori students had a slightly higher median hourly rate $(\$ 6.00)$ than the New Zealand European students (\$5.90).

The median pay rates for the most popular occupational groups were:

$\begin{array}{lr}\text { Supermarket workers } & \$ 5.37 \\ \text { Other retail workers } & \$ 5.73 \\ \text { Cleaners } & \$ 10.00 \\ \text { Fast food } & \$ 9.71 \\ \text { Babysitters } & \$ 5.25\end{array}$

Newspaper deliverers, according to the questionnaires seemed to be paid a flat rate per round per week. If the round takes them half an hour each day then their pay seems quite reasonable in comparison with the other workers. If their round takes them two hours they appear to be very poorly paid. In the research that David Hanna and I presented at the last conference, we left the newspaper delivers included in the pay data, calculating an hourly rate from the hours the workers stated and their weekly pay rates. This resulted in some very low figures. This is why I have excluded them from the calculations this time and treated them separately. The calculated hourly rates for the newspaper deliverers in this sample range from $\$ 1.67$ to $\$ 11.67$.

From 31 March this year a statutory minimum wage was introduced applying to all employees aged 16 and over. 
This rate was set at $\$ 3.68$ per hour. Five of the students aged 16 or over in the sample earned less than this rate. However none of these five were paying tax on their earnings. None of the 15 year olds were earning less than the minimum wage even though they are not affected by it. Three restaurant workers who were paying tax on their earnings were being paid $\$ 3.70$ an hour (two were aged 16 , one aged 17).

When I told the students in the focus groups what the Youth Minimum Wage was, the general reaction was "Do people really work for that?"

Most of the students thought that their pay was fair for the work that they did (56 percent). However, 27\% did not, and a further 15 percent did not know. Predictably, those who thought their pay was fair earned more than those who didn't.

\section{Penal Rates}

Nineteen percent of the students were paid penal rates mainly those who had been in their jobs for more than 12 months. It was the supermarket and other retail workers who were most likely to be being paid penal rates ( 26 percent of supermarket workers and 35 percent in other retail work).

\section{Paid holidays}

The students were asked: "Apart from statutory holidays (i.e. Christmas, Easter, Waitangi Day etc.), do you get any paid holidays?"

Twenty eight percent of the students said that they got paid holidays, 50 percent said that they did not and 21 percent did not know. A disproportionate number of the students who did not get paid holidays worked in smaller worksites (five or fewer workers). The students in one of the focus groups noted that even when they were entitled to holidays it was hard to get time off and they knew of many students who had quit their jobs at Christmas time so that they could have a break because they were not allowed to take their leave which was due.

Under the Holidays Act, employees are entitled to at least three weeks paid leave after they have worked for the same employer continuously for twelve months. When the data is analysed in terms of length of employment, 40 percent of those working for more than one year got paid holidays, 51 percent did not and 9 percent did not know if they did or not.

To clarify the situation further, I excluded all those who said that they did not pay tax on the money that they earned. The situation improved slightly - of the 55 students who had been working for one year or more who paid tax on their earnings, 23 (i.e. 42 percent) did not get paid holi- days. This included 4 of the 14 supermarket workers in this category, 3 of the 8 other retail workers, and 4 of the 6 cleaners.

\section{Sick/special leave}

The students were asked specifically about sick leave: "Do you get paid if you are sick and unable to work for a day?"

Twenty percent said that they did get paid, 64 percent that they didn't, and 15 percent did not know. Again, a disproportionate number of the students who were not getting sick leave worked in smaller workplaces (5 or fewer workers).

Employees are entitled to five days special leave for the next twelve months after they have been working for the same employer for more than six months. This leave covers sick, domestic and bereavement leave.

Once again I broke the data down into length of employment. Twenty four percent of those working six months or more got sick leave, 68 percent did not, and 8 percent didn't know.

Of those paying tax, 30 percent got sick leave, 60 percent did not and 10 percent didn't know whether they did or not. 15 of the 30 supermarket workers who had worked for more than 6 months and paid tax, 10 of the 13 other retail workers and all six of the cleaners were not getting paid sick leave.

\section{Training}

Fifty five percent said that they received some type of training for their jobs; table 5 .

Table 5. Training by Type of Work

\begin{tabular}{ll}
\hline Type of Work & $\begin{array}{l}\text { Proportion } \\
\text { who had training }\end{array}$ \\
\hline Supermarket Workers & $87 \%$ \\
Fast food & $76 \%$ \\
Other Retail & $52 \%$ \\
Newspaper delivers & $40 \%$ \\
Cleaners & $21 \%$ \\
Babysitters & $0 \%$ \\
\hline
\end{tabular}

In further analysis of this area I intend to look at the adequacy of this training from the students' perspective. It is clear from the questionnaires that some have had a lot of training for their jobs (two week training courses for example) while others had less:

They told me what to do and showed me how to do it for about quarter of an hour on the first day, not really training, but that's as close to being trained as I got. 


\section{Employment Contracts}

\section{Individual/ collective}

Just under half the students said that they did not know if they had an individual or collective contract. Eleven of the students (5 percent) said that they did not have a contract. Of those that did know 66 percent were on individual contracts ( 30 percent of the total) and 34 percent were on collective contracts (15 percent of the total).

The gender difference for this question was quite marked. Fifty eight percent of female students compared to 35 percent of male students did not know what type of contract they had. Of those that did know, 62 percent of the females had individual contracts compared to 72 percent of the male students

The biggest groups of workers on individual contracts were the supermarket workers (41 percent) and the cleaners (42 percent). Fifty three percent of the cleaners did not know what type of contracts they had. Of the six child care workers, five said that they did not know what type of contract they had, and the other one said they didn't have a contract.

\section{Written /vrbal Contracts}

As with individual/collective contracts, a large proportion of the students ( 25 percent) did not know whether they had a written or verbal contract. Of those that did know, 64 percent had written contracts.

Again more of the female students (29 percent) did not know whether their contract was written or verbal than the male students (16 percent). However, of those that did know there was very little difference between the male and female students in the proportion written and verbal contracts.

The most likely group to have written contracts were supermarket workers ( 85 percent). The baby-sitters were the most likely to have verbal contracts - though one did have a written contract.

\section{Input into contract}

Just over half ( 51 percent) of the students said that they had no input into their employment contract and/or conditions. Two percent discussed their contracts with their union (reflecting the low level of union membership), and 39 percent discussed them with their employer.

The group which records the least level of input into their contracts and/or conditions are the newspaper deliverers with 80 percent saying they had no input.

\section{Feelings about their contracts and conditions}

Most of the students felt that their employment contract and conditions of work were good or okay (66 percent).
Twelve percent thought they were not okay (or worse). Some of the students very clear about their negative feelings about their contracts and conditions:
"They suck"
“...They expect more than is humanly possible and they try and get away with giving us as little money, with as little equipment and as little time as possible."

The least satisfied and most dissatisfied group were the supermarket workers. Only 61 percent of this group felt their conditions were good or okay, whereas 20 percent thought they were not okay. The most satisfied group were the other retail workers.

\section{Future research}

This paper is a starting point in the analysis of the information collected for my thesis. Since presenting this paper at LEW, many of the questions raised here have been addressed in the thesis.

Other important issues discussed in the thesis which are not presented here include: what happens in the students' workplace; the reasons why they work; what they do with the money they eam; and the effects work has on schooling.

Any future research in the area of employment conditions of student workers, I feel, needs to move away from the question 'Are these workers exploited?' The next step is to recognise that some student workers are exploited, and focus research on the best ways to combat or prevent this.

\section{Conclusion}

I am concerned by the large proportions of students who say they are not getting the paid sick leave or holidays that they are entitled to by law. Forty two percent of those entitled are missing out on holidays, and $60 \%$ missing out on sick leave.

It needs to be asked why the numbers missing out are so high. Are the students ignorant of their rights or are they just not insisting on them? Are their employers ignorant of the law or are just ignoring their obligations? I suspect that it is a mixture of all of these factors, but further research is needed to confirm this as my research only looks at student employment from the students' perspective, not the employers'. As far as the students are concerned though, from the focus groups it is clear that in many cases, even when they do know what their rights are, they will not press for them in case they lose their jobs.

What is also conceming is the significant numbers of students who do not know even basic facts about their employment contract or conditions. It is disturbing that so many of the students didn't know if they got sick leave or holidays. Even larger numbers had no idea if they were on 
an individual or collective contract.

Two years ago in the Young Workers Survey, we expressed concern about the low level of knowledge of employment contracts of the workers in our sample. At that point in time I thought that this high level of ignorance could be due to the relatively new introduction of the Employment Contracts Act (Hanna and Peterson 1992).

However, the proportion of students in this more recent research who did not know whether they had individual or collective contracts is more than ten percent higher than in the previous survey.

The students in the focus groups said that they had been taught about the Employment Contracts Act in class. If students are being taught about employment contracts in school, why are they not then relating what they hear in class to their own experiences?

\section{References}

Aschenden, D. 1990 The Student Workers: The extent, character, consequences and possibilities of parttime work by secondary students. Department of Employment, Education and Training, Australia.

Boyd, S. 1993 Youth minimum wage debate heats up Evening Post, 20 December: 11

Hanna, D. \& Peterson, D. 1993 Young People in the New Labour Relations Environment: An Exploratory Survey. In Morrison, P. (ed), Labour, Employment and Work in New Zealand: Proceedings of the Fifth Conference, November 12 \& 13, 1992

Parker, S. 1990 Child Labour: blood, sweat and two dollars an hour. North and South, June: 98-109

Sultana, R. 1990 Breaking them in? School kids in the twilight economy NZ Journal of Industrial Relations, 15:19-33

Swain, P. 1990 Students work to make it at school Dominion Sunday Times, 26 August: 16

\section{Author}

Debbie Peterson is a Social Science Research Masters Student at Victoria University of Wellington, PO Box 600 , Wellington. 